\title{
Apical Extracellular Calcium/Polyvalent Cation-sensing Receptor Regulates Vasopressin-elicited Water Permeability in Rat Kidney Inner Medullary Collecting Duct
}

\author{
J.M. Sands, ${ }^{\star}$ M. Naruse, ${ }^{\star}$ M. Baum, ${ }^{\ddagger}$ I. Jo, ${ }^{\ddagger}$ S.C. Hebert, ${ }^{\S}$ E.M. Brown,, and H.W. Harris ${ }^{\ddagger}$ \\ *Renal Division, Emory University School of Medicine, Atlanta, Georgia 30322; ${ }^{\ddagger}$ Division of Nephrology, Children’s Hospital, Boston, \\ Massachusetts 02115; ${ }^{\S}$ Renal Division and ${ }^{\|}$Endocrine-Hypertension Division, Department of Medicine, Brigham and Women's Hospital, \\ Boston, Massachusetts 02115
}

\begin{abstract}
During antidiuresis, increases in vasopressin (AVP)-elicited osmotic water permeability in the terminal inner medullary collecting duct (tIMCD) raise luminal calcium concentrations to levels ( $\geq 5 \mathrm{mM}$ ) above those associated with the formation of calcium-containing precipitates in the urine. Calcium/polycation receptor proteins (CaRs) enable cells in the parathyroid gland and kidney thick ascending limb of Henle to sense and respond to alterations in serum calcium. We now report the presence of an apical $\mathrm{CaR}$ in rat kidney tIMCD that specifically reduces AVP-elicited osmotic water permeability when luminal calcium rises. Purified tIMCD apical membrane endosomes contain both the AVP-elicited water channel, aquaporin 2 , and a $\mathrm{CaR}$. In addition, aquaporin 2-containing endosomes also possess stimulatory $\left(\mathbf{G}_{\mathrm{\alpha q}} /\right.$ $\left.G_{\alpha 11}\right)$ and inhibitory $\left(G_{\alpha i 1,2 \text {, and 3 }}\right)$ GTP binding proteins reported previously to interact with CaRs as well as two specific isoforms (delta and zeta) of protein kinase $\mathrm{C}$.

Immunocytochemistry using anti-CaR antiserum reveals the presence of $\mathrm{CaR}$ protein in both rat and human collecting ducts. Together, these data provide support for a unique tIMCD apical membrane signaling mechanism linking calcium and water metabolism. Abnormalities in this mechanism could potentially play a role in the pathogenesis of renal stone formation. (J. Clin. Invest. 1997. 99:1399-1405.) Key words: vasopressin $\bullet$ nephrolithiasis - water channels • epithelial cell $\bullet$ membrane transport
\end{abstract}

\section{Introduction}

Calcium-containing kidney stones are caused by the formation and subsequent growth of calcium oxalate or phosphate crystals in the tubules of the kidney medulla. It is a common disorder in developed countries (1) with incidence rates as great as $0.3-1 \%$ in the United States (2). While as many as $40 \%$ of affected individuals exhibit hypercalciuria, the remainder excrete normal quantities of urinary calcium $(2,3)$. The total uri-

Address correspondence to H. William Harris, Renal Research Laboratory, Division of Nephrology, Enders Building Room 1260, Children's Hospital, 300 Longwood Avenue, Boston, MA 02115. Phone: 617-355-6989; FAX: 617-730-0435; E-mail: harris@a1.tch.harvard.edu

Received for publication 5 June 1996 and accepted in revised form 12 December 1996.

J. Clin. Invest.

(c) The American Society for Clinical Investigation, Inc.

0021-9738/97/03/1399/07 \$2.00

Volume 99, Number 6, March 1997, 1399-1405 nary calcium concentration of normal humans ingesting a low $(10 \mathrm{mM})$ calcium diet with unrestricted access to fluids has been estimated as $2.3 \pm 0.3 \mathrm{mM}(4)$. However, urinary calcium concentrations may rise significantly above this value when water intake is restricted since increases in arginine vasopressin $(\mathrm{AVP})^{1}$-elicited osmotic water permeability $\left(\mathrm{P}_{\mathrm{f}}\right)$ in collecting duct stimulate water reabsorption selectively via aquaporin 2 (AQP-2) water channels. Intervals of antidiuresis have been implicated in both the increased incidence of nephrolithiasis in hot dry regions (5) as well as the substantial risk of recurrent stone formation in patients with nephrolithiasis (6).

Conversely, hypercalcemia and the resulting hypercalciuria produce a renal concentrating defect characterized by inner medullary collecting duct (IMCD) resistance to either endogenous or exogenous AVP (7). Since elevated extracellular calcium has no effect on basolateral AVP-dependent cAMP production by the IMCD (8), it is possible that calcium may exert its effects elsewhere within IMCD epithelial cells.

The molecular cloning of extracellular calcium/polyvalent cation receptor proteins ( $\mathrm{CaRs}$ ) from bovine (9) and human (10) parathyroid glands as well as rat kidney (RaKCaR) (11), combined with studies of patients possessing $\mathrm{CaR}$ mutations and exhibiting abnormalities in calcium metabolism (12) have established the central role of the $\mathrm{CaR}$ in calcium homeostasis. When expressed in Xenopus oocytes, these CaRs are activated by increases in calcium as well as by other polycations including neomycin. The availability of probes for RaKCaR (11) and AQP-2 $(13,14)$ from rat kidney as well as methodologies both to quantify AVP-elicited $\mathrm{P}_{\mathrm{f}}$ in isolated perfused rat terminal portion of the IMCD (tIMCD) (15) and to purify AQP-2 endosomes derived from the IMCD apical membrane (16) enabled us to define components of a CaR-mediated sensing mechanism in the apical membrane of these epithelial cells that may provide a link between calcium and water homeostasis.

\section{Methods}

Tubule perfusion. IMCD that were dissected from the terminal two thirds of kidney medullae from Sprague-Dawley rats were mounted on concentric pipettes, perfused at $37^{\circ} \mathrm{C}$, and both $\mathrm{P}_{\mathrm{f}}$ as well as $\mathrm{P}_{\text {urea }}$ determined as described previously (15). For measurement of $P_{f}$, the bath solution contained $(\mathrm{mM}): 223 \mathrm{NaCl}\left(123 \mathrm{mM} \mathrm{NaCl}\right.$ for $\left.\mathrm{P}_{\text {urea }}\right), 25$ $\mathrm{NaHCO}_{3}, 2 \mathrm{CaCl}_{2}, 2.5 \mathrm{~K}_{2} \mathrm{HPO}_{4}, 1.2 \mathrm{MgSO}_{4}, 5.5$ glucose, 4 creatinine,

1. Abbreviations used in this paper: $\mathrm{AQP}$, aquaporin water channel protein; AVP, arginine vasopressin; CaR, extracellular calcium/polyvalent cation receptor protein; IMCD, inner medullary collecting duct; $\mathrm{P}_{\mathrm{f}}$, osmotic water permeability; PKC, protein kinase C; RaK$\mathrm{CaR}$, rat kidney $\mathrm{CaR}$; TAL, thick ascending limb of Henle; tIMCD, terminal portion of the IMCD. 
and 5 urea. AVP $\left(10^{-10} \mathrm{M}\right.$, Sigma Chemical Co., St. Louis, MO) was added to the bath solution. The luminal perfusate solutions were identical to the bath solution except for the use of: (a) $123 \mathrm{mM} \mathrm{NaCl}$; (b) 0,1 , or $5 \mathrm{mM} \mathrm{CaCl}_{2} ;(c)$ addition of $200 \mu \mathrm{M}$ neomycin in selected experiments; and (d) $5 \mathrm{mM}$ raffinose and $0 \mathrm{mM}$ urea for $\mathrm{P}_{\text {urea }}$ experiments. Data from three to four collections were averaged to obtain a single value for each experimental condition for each tubule. These average values were analyzed by analysis of variance followed by a multiple comparison protected $t$ test with $P<0.05$ indicating statistical significance.

Immunocytochemistry. Kidneys of anesthetized rats were fixed by perfusion with freshly prepared $4 \%$ paraformaldehyde (17) and frozen sections cut from the tip of individual kidney medullae. Unfixed human kidney tissue from pathological specimens obtained from patients undergoing nephrectomy for renal cell carcinoma was frozen after embedding in O.C.T. compound (Miles Laboratories, Inc., Elkhart, IN). Immunocytochemistry using four different antisera was performed as described previously (18) on sections counterstained with $0.1 \%$ methylene green. Affinity purified anti-AQP-2 antiserum raised against a peptide (AQP-2, amino acids 258-271) was used as described previously (14). Affinity purified anti-AQP-3 and -AQP-4 antisera were also raised in rabbits and purified in a manner identical to that described for AQP-2 using peptides (AQP-3, amino acids 263-277 or AQP-4, amino acids 277-292). Rabbit anti-CaR antiserum was raised against a peptide (bovine CaR (9), amino acids 215-237) as described previously (19). The specificity of binding of anti-AQP-2,-AQP-3, and -AQP-4 were each confirmed by preincubation of antiserum with a 100-fold molar excess of peptide as described for CaR in Fig. 2 (data not shown).

Immunoblotting. Proteins of purified apical membrane endosomes from rat IMCD were analyzed by immunoblotting using chemiluminescence detection as described previously (16). After SDS-PAGE and electrophoretic transfer of proteins from the gel to a nitrocellulose filter, strips corresponding to individual gel lanes were incubated with one of the antisera listed below. After washing and exposure to affinity purified peroxidase-conjugated secondary antisera, these strips were reassembled into a single collection that was subsequently developed using chemiluminesence (ECL, Amersham Corp., Arlington Heights, IL) to produce a montage of gel strips on a single x-ray film.
A
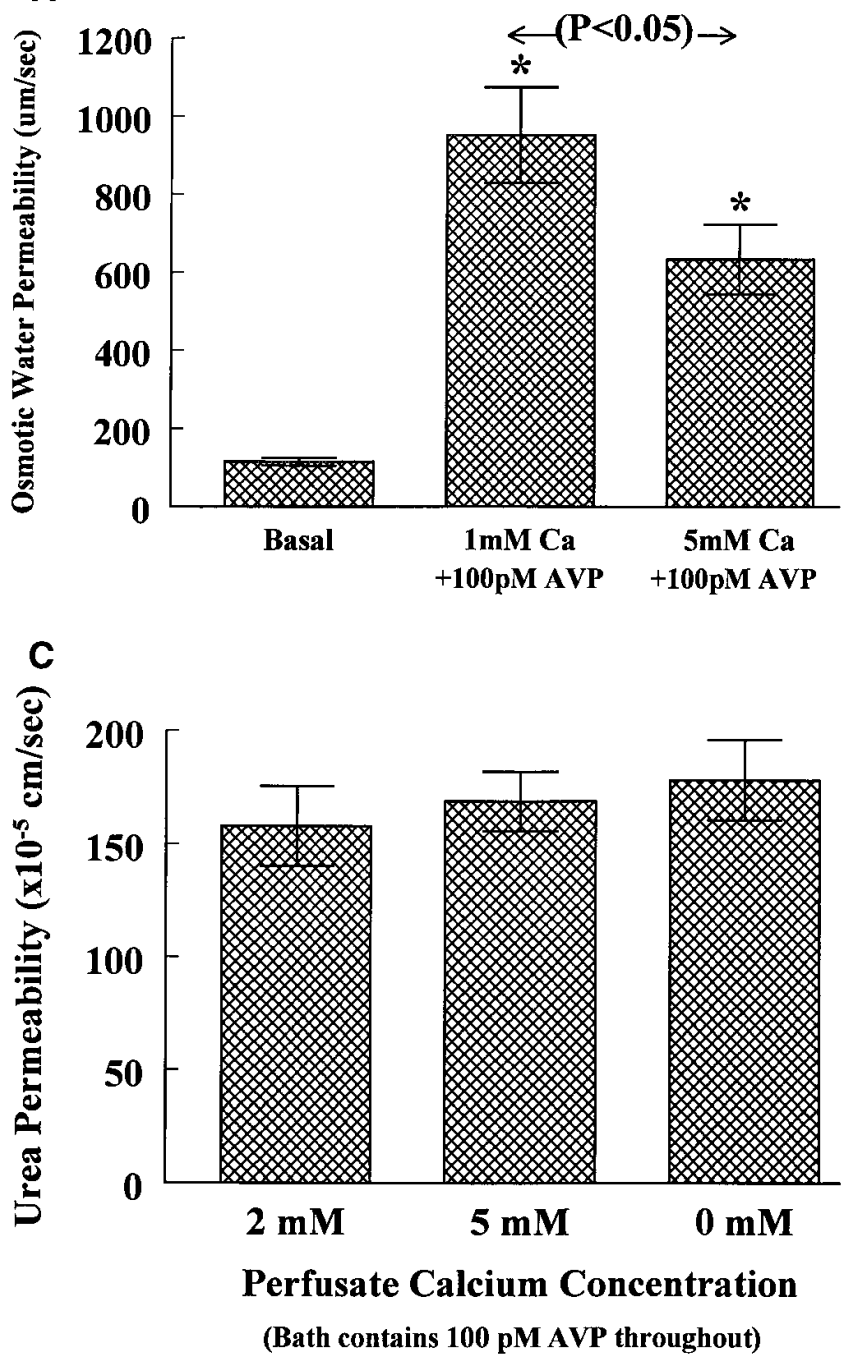

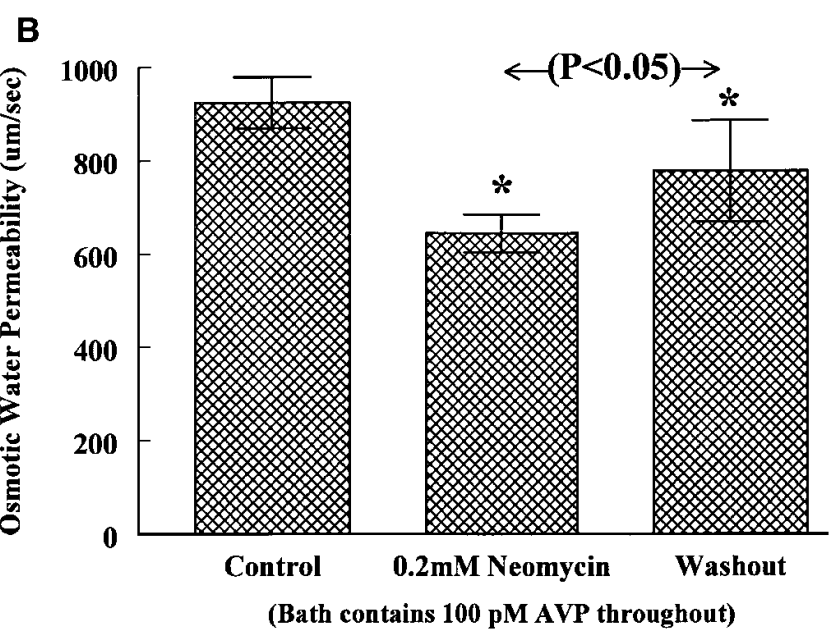

Figure 1. Summary of data showing that AVP-elicited $\mathrm{P}_{\mathrm{f}}$ but not $\mathrm{P}_{\text {urea }}$ of isolated perfused rat tIMCD is inhibited reversibly by inclusion of $\mathrm{CaR}$ agonists in the luminal perfusate. All perfusion data displayed in $A-C$ were obtained in paired experiments where $\mathrm{P}_{\mathrm{f}}$ and $\mathrm{P}_{\text {urea }}$ values are reported as mean \pm SE. $(A)$ An increase of luminal calcium from 1 to 5 $\mathrm{mM}$ causes a reversible $30 \%$ reduction in tIMCD $\mathrm{P}_{\mathrm{f}}$. The $\mathrm{P}_{\mathrm{f}}$ of isolated tIMCDs were determined as described previously (15) in the presence of a $200 \mathrm{mosM} / \mathrm{kg} \mathrm{H}_{2} \mathrm{O}$ bath to lumen osmotic gradient. While the bath solution superfusing the basolateral surface of tubules (see Methods for composition of solutions) always contained $2 \mathrm{mM}$ calcium, the luminal perfusate solutions contained either 1 or $5 \mathrm{mM}$ calcium. The basal (AVP-independent) $\mathrm{P}_{\mathrm{f}}$ of tIMCDs $(115 \pm 9 \mu \mathrm{m} / \mathrm{s}, n=6)$ was significantly $(P<0.0001)$ increased by adding AVP $\left(10^{-10} \mathrm{M}\right)$. The AVPelicited $\mathrm{P}_{\mathrm{f}}(952 \pm 123 \mathrm{~mm} / \mathrm{s}, n=6)$ obtained in the presence of $1 \mathrm{mM} \mathrm{lu}-$ minal calcium was significantly $(P<0.0009)$ higher than with a luminal perfusate containing $5 \mathrm{mM}$ calcium $(633 \pm 89 \mu \mathrm{m} / \mathrm{s}, n=6)$. This difference in AVP-elicited $P_{f}$ was independent of whether tubules were studied first with $1 \mathrm{mM}$ luminal calcium and then $5 \mathrm{mM}$ or in the reverse order. (B) Exposure of tIMCD to the CaR agonist, neomycin, also results in a similar reduction in AVP-elicited $\mathrm{P}_{\mathrm{f}}$. The stable AVP-elicited $\mathrm{P}_{\mathrm{f}}$ of perfused tICMDs (Control) as described in $A$ underwent a similar $30 \%$ significant $(P<0.0001)$ reduction upon luminal perfusion of

tIMCD with $200 \mu \mathrm{M}$ neomycin in the presence of $1 \mathrm{mM}$ calcium (938 $\pm 64 \mathrm{vs.} 644 \pm 41 \mu \mathrm{m} / \mathrm{s}, n=6$ ). This decrease in $\mathrm{P}_{\mathrm{f}}$ was partially reversible $(778 \pm 109 \mu \mathrm{m} / \mathrm{s}, n=6)$ upon removal of neomycin (Washout). (C) AVP-elicited $\mathrm{P}_{\text {urea }}$ is not changed by $0-5 \mathrm{mM}$ alterations in luminal calcium in tIMCD. The stable $\mathrm{P}_{\text {urea }}$ of AVP-stimulated tIMCD $(n=6)$ is not altered significantly $(P>0.2)$ when perfused with various luminal solutions containing either $2 \mathrm{mM}\left(158 \pm 18 \times 10^{-5} \mathrm{~cm} / \mathrm{s}, n=4\right), 5 \mathrm{mM}\left(169 \pm 13 \times 10^{-5} \mathrm{~cm} / \mathrm{s}, n=4\right)$, or $0 \mathrm{mM}\left(178 \pm 18 \times 10^{-5} \mathrm{~cm} / \mathrm{s}, n=4\right) \mathrm{calcium}$. 
Primary antisera used included: $(a)$ anti-AQP-2 $(1: 2,000)(14)$, (b) anti-CaR $(1: 3,000),(19),(c)$ anti- $\mathrm{G}_{\alpha q} / \mathrm{G}_{\alpha 11}(1: 10,000)$ (gift of A. Tashjian, Harvard University, Boston, MA), $(d)$ anti- $\mathrm{G}_{\mathrm{i} \alpha 1-2}(1: 1,000)$ and $\mathrm{G}_{\mathrm{i} \alpha 3}(1: 3,000)$ (Upstate Biotechnology Inc., Lake Placid, NY), or (e) anti-protein kinase $\mathrm{C}$ isozymes $\alpha, \beta 1, \beta 2, \gamma, \delta, \epsilon$, and $\zeta$ (all dilutions, 1:3,000)(GIBCO BRL, Gaithersburg, MD).

RNA blotting analyses. Poly $\left(\mathrm{A}^{+}\right)$RNA was prepared from various regions of rat kidney as described previously (20), fractionated by denaturing agarose gel electrophoresis, transferred to nylon membranes (Duralon-UV; Stratagene Inc., La Jolla, CA) whereupon blots were probed $\left(2 \times 10^{6} \mathrm{cpm} / \mathrm{ml}\right)$ with a ${ }^{32} \mathrm{P}$-labeled cDNA (NE Blot Kit; New England Biolabs Inc., Beverly, MA) containing nucleotides 1-1566 of the extracellular domain of $\mathrm{RaKCaR}$ and autoradiography performed as described previously (20).

\section{Results}

Previous studies of isolated perfused rat tIMCD show that the apical membrane is the rate limiting barrier for transepithelial water flux $(21,22)$ with separate pathways for AVP-elicited water and urea transport $(15,21)$. In this study, perfused rat tIMCD displayed a low basal (AVP-independent) $\mathrm{P}_{\mathrm{f}}$ that is not altered when the luminal perfusate calcium concentration is either 1 or $5 \mathrm{mM}$ (Fig. $1 A$ ). As reported previously (15) and shown in Fig. $1 A, 10^{-10} \mathrm{M}$ AVP elicits a rapid, sustained eightfold increase in tIMCD $\mathrm{P}_{\mathrm{f}}$ when the luminal calcium concentration is $1 \mathrm{mM}$ (under these conditions, the cytosolic calcium concentration of tIMCD cells is not altered significantly by AVP; reference 23). However, Fig. 1 demonstrates that the AVP-elicited $\mathrm{P}_{\mathrm{f}}$ underwent a significant, rapid ( $<10 \mathrm{~min}$ ) $30 \%$ reduction when the luminal perfusate was changed to an identical solution containing either $5 \mathrm{mM}$ calcium (Fig. $1 A$ ) or 200 $\mathrm{mM}$ neomycin (Fig. $1 B$ ). The inhibition of AVP-elicited $\mathrm{P}_{\mathrm{f}}$ was fully or partially reversed when the luminal perfusate was replaced with a solution containing either $1 \mathrm{mM}$ calcium or lacking neomycin, respectively. The effect of increased luminal calcium was specific for AVP-elicited $\mathrm{P}_{\mathrm{f}}$ since perfusion of tubule lumens with either 0,2 , or $5 \mathrm{mM}$ calcium did not significantly alter the AVP-mediated increase in urea permeability $\left(\mathrm{P}_{\text {urea }}\right.$ ) (Fig. $1 \mathrm{C}$ ). Taken together, these data provide functional evidence for the presence of a calcium sensing system at the apical membrane of tIMCD cells that responds to increases in luminal calcium concentrations by specific reductions in AVP-stimulated $\mathrm{P}_{\mathrm{f}}$ without change in $\mathrm{P}_{\text {urea }}$.

Previous reports (17) have demonstrated that optimal preservation of the morphology of epithelial cells in the deep inner medulla of rat kidney is achieved using solutions that are hypertonic with respect to plasma osmolality. Immunohistochemistry of rat kidney medulla preserved by hypertonic fixation conditions and probed with anti-CaR antiserum displays specific staining of tIMCD (Fig. $2 d$ ) that was ablated by preincubation of antiserum with excess specific peptide (Fig. $2 e$ ). In rat kidney, the staining intensity of the CaR protein was most
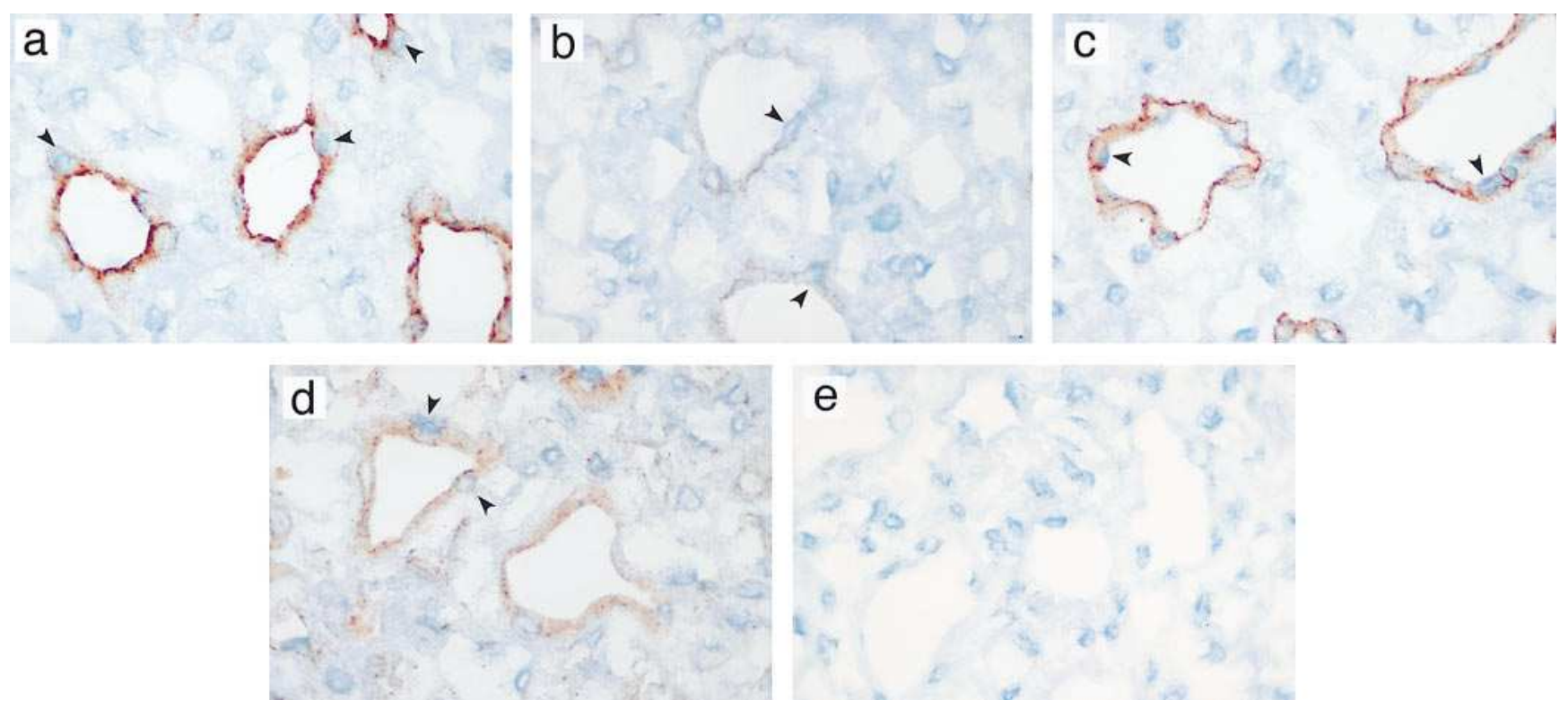

Figure 2. Anti-CaR antiserum localizes a CaR protein to the apical membrane region of rat kidney tIMCD. 4- $\mu$ m-thick frozen sections of rat kidney terminal medulla fixed in vivo by perfusion with $4 \%$ paraformaldehyde under hypertonic conditions (17) were used for immunocytochemistry (18) using four different rabbit anti-peptide antisera. Antibody binding was detected using an affinity-purified peroxidase-conjugated donkey anti-rabbit antiserum and aminoethylcarbazole that stains as a rose-colored reaction product. (A) Anti-AQP-2 antiserum (dilution 1:25,000) localizes AQP-2 protein predominantly to the region of the apical membrane as reported previously (14). Note prominent staining of AQP-2 between nuclei (small arrowheads) and IMCD lumen. (B) Anti-AQP-3 antiserum (dilution 1:1,000) localizes AQP-3 protein predominantly to the region of the IMCD basolateral membrane as reported previously (23). Note interposition of nuclei (small arrowheads) and cytoplasm between AQP-3 and lumen. $(C)$ Anti-AQP-4 antiserum (dilution 1:300) localizes AQP-4 protein predominantly to the basolateral membrane as reported previously (24). Again note interposition of nuclei (small arrowheads) between AQP-4 staining and tubule lumen. $(D)$ Anti-CaR antiserum (19) (dilution 1:1,600) localizes CaR protein in the IMCD in a punctate distribution in the region of the apical membrane between the lumen and nuclei (small arrowheads). (E) Anti-CaR peptide antiserum preincubated with a 100-fold molar excess of CaR peptide before immunocytochemistry causes ablation of $\mathrm{CaR}$ staining. All photomicrographs $(594 \times)$ are from sections derived from a single rat and are representative of a total of 10 separate experiments using different animals. 


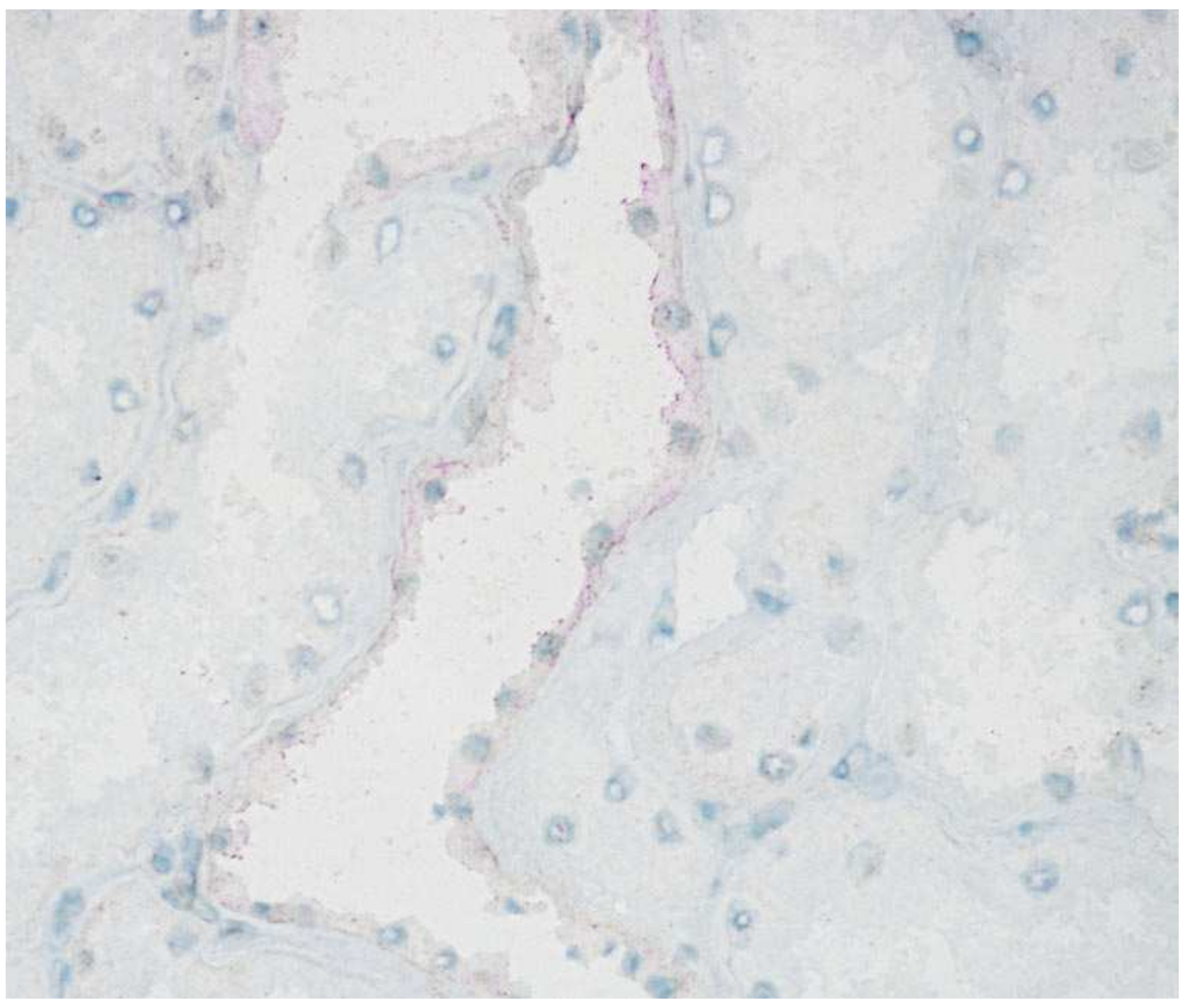

Figure 3. Normal human kidney collecting duct displays $\mathrm{CaR}$ staining similar to that exhibited by rat IMCD. Immunocytochemistry staining of frozen sections of unfixed human kidney as described in Fig. 2 using anti-CaR antiserum reveals prominent staining of epithelial cells of large collecting ducts. This photomicrograph $(375 \times)$ is representative of a total of four separate experiments using three different human kidneys. prominent in the terminal third of IMCD compared with the initial and middle portions (data not shown). Isotonic fixation of the hypertonic medullary tissue resulted in a greatly diminished intensity of both CaR and AQPs 2, 3, and 4 as described below. As shown in, Fig. 2, $a-c$, we compared the distribution of $\mathrm{CaR}$ staining in these sections to those displayed by three different antisera, each specific for a distinct AQP water channel protein previously reported to be localized predominantly to either the apical region (AQP-2, reference 14, Fig. $2 a$ ) or basolateral regions (AQP-3, reference 24, Fig. $2 b$ and AQP-4, reference 25, Fig. $2 c$ ) of IMCD cells. The distribution of $\mathrm{CaR}$ staining was similar to that of AQP-2, suggesting that the tIMCD CaR protein is most abundant in the apical region of the IMCD cell.

Immunocytochemistry of frozen sections of human kidney also reveals abundant CaR staining in epithelial cells of large collecting ducts despite an inability to obtain normal human kidney tissue preserved by hypertonic fixation (Fig. 3).

We have reported recently (19) that this same anti-CaR antiserum binds to proteins of 135 and $200-250 \mathrm{kD}$ on immunoblots of crude membranes prepared from rat kidney cortex. These two bands may correspond to monomeric and dimeric forms of the glycosylated CaR polypeptide of $121 \mathrm{kD}$ as predicted by cDNA sequencing and observed as in vitro translation products (9). To determine whether a $\mathrm{CaR}$ protein is a constituent of highly purified endosomes derived from the apical membrane of tIMCD that contain abundant AQP-2 (16), endosomes were immunoblotted using anti-CaR antiserum. As shown in Fig. $4 A$, these purified endosomes contain both 135- and 240-kD CaR protein bands.

Previous RNA blotting analyses (11) of rat kidney poly

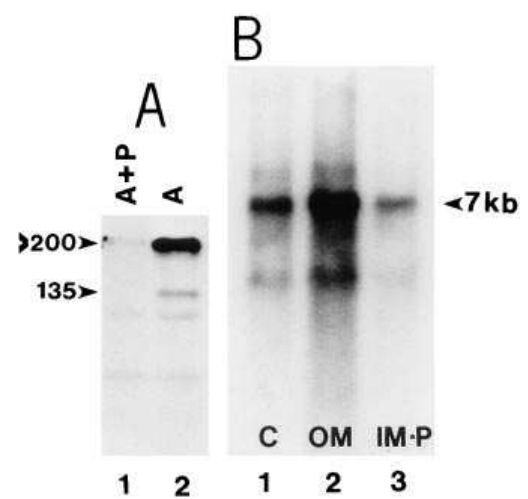

Figure 4. A combination of immunoblotting and Northern analyses demonstrates the expression of a CaR protein in the terminal portion of rat IMCD. $(A)$

Purified AQP-2 containing endosomes possess a $\mathrm{CaR}$ protein. APQ-2 endosomes were prepared from the terminal third of rat kidney medulla and 40 $\mu \mathrm{g}$ of purified endosomal protein/lane subjected to immunoblotting analyses as described previously (16) using the anti-CaR antiserum (1:3,000 dilution) displayed in Figs. 2 and 3. The anti-CaR antiserum $(A)$ identifies two bands of 135 and 200-250 kD (lane 2) under conditions where the staining of bands was ablated upon preincubation of anti-CaR antiserum with a 100 -fold molar excess of $\mathrm{CaR}$ peptide $(A+P$, lane 1$)$. These data are derived from a single representative experiment performed a total of four times. $(B)$ Poly $\left(\mathrm{A}^{+}\right)$RNA from rat terminal deep medulla contains a $\mathrm{CaR}$ transcript. $10 \mu \mathrm{gs}$ of poly $\left(\mathrm{A}^{+}\right) \mathrm{RNA}$ from cortex $(C$, lane 1$)$, outer medulla $(O M$, lane 2$)$, and the terminal third of inner medulla (IM-P, lane 3$)$ were subjected to RNA blotting analysis as described previously (19) using a ${ }^{32} \mathrm{P}$-labeled partial RaK$\mathrm{CaR}$. After washing under high stringency conditions $(0.5 \times \mathrm{SSC}$, $0.1 \% \operatorname{SDS}, 65^{\circ} \mathrm{C}$ ), the filter was subjected to autoradiography for $20 \mathrm{~h}$. These data shown here are from a single representative experiment performed a total of six times. 
$\left(\mathrm{A}^{+}\right)$RNA showed that RaKCaR transcripts of 7-7.5 and $4 \mathrm{~kb}$ are present in cortex and outer medulla, but only a faint $7-7.5-\mathrm{kb}$ transcript is observed in inner medulla. To verify our immunolocalization of $\mathrm{CaR}$, poly $\left(\mathrm{A}^{+}\right) \mathrm{RNA}$ from the terminal portion of the inner medulla was probed with a ${ }^{32} \mathrm{P}$-labeled $\mathrm{RaK}$ CaR cDNA and shows a prominent 7-7.5-kb band (Fig. 4 B). On the basis of these data shown in Figs. 1, 2, and 4, we suggest that rat IMCD cells express a functional $\mathrm{CaR}$ protein on their apical membrane.

Previous studies in parathyroid (26), thyroid (27), and kidney $(28)$ tissues as well as Xenopus oocytes $(9,29)$ have suggested that $\mathrm{CaRs}$ interact with multiple $\mathrm{G}$ protein species including $G_{\alpha i}(8,27,29)$ and $G_{\alpha q} / G_{\alpha 11}(9,26,28)$ to either inhibit basolateral adenylyl cyclase activity (8) or activate phosphoinositide-specific phospholipase $\mathrm{C}$ signal transduction pathways that regulate epithelial cell transport in thick ascending limb of Henle (TAL) (30), membrane vesicle traffic (31), as well as increase intracellular calcium and activate a variety of protein kinase $\mathrm{C}(\mathrm{PKC})$ isoforms $(9,27)$. To determine if such signal transduction proteins are present in apical endosomes containing AQP-2, where they might form a functional complex to regulate apical membrane $\mathrm{P}_{\mathrm{f}}$, we performed immunoblotting analyses (Fig. 5) of endosomes using antisera specific for $\mathrm{G}_{\alpha \mathrm{q}} / \mathrm{G}_{\alpha 11}$ (Fig. $5 A$ ) and $\mathrm{G}_{\mathrm{i} \alpha 1-3}$ (Fig. $5 \mathrm{~B}$ ) as well as seven PKC isoforms (Fig. $5 C$ ). As shown in Fig. 5 A, purified endosomes possess abundant AQP-2 protein (Fig. $5 \mathrm{~A}$, lane 1 ) displayed as bands of 29 and $30-45 \mathrm{kD}$, as well as a $42-\mathrm{kD}$ band (Fig. $5 \mathrm{~A}$, lane 3 ) identified by anti- $\mathrm{G}_{\alpha q} / \mathrm{G}_{\alpha 11}$ antiserum that comigrates with a corresponding band present in a membrane fraction prepared from cultured AT-20 parathyroid cells shown previously (26) to possess $\mathrm{G}_{\alpha q} / \mathrm{G}_{\alpha 11}$ protein (Fig. $5 \mathrm{~A}$, lane 4). This $42-\mathrm{kD}$ band was not present when AQP-2 endosomes were immunoblotted using the corresponding preimmune antiserum (Fig. $5 A$, lane 2). Similar analyses (Fig. $5 B$ ) were performed using antisera specific for $\mathrm{G}_{\mathrm{i} \alpha 1-2}$ (Fig. 5 B, left) and $\mathrm{G}_{\mathrm{i} \alpha 3}$ (Fig. 5 B, right). Both antisera identified corresponding 41-kD bands that were enriched in purified AQP-2 endosomes (Fig. 5 $B$, lane 3 ) when compared with total protein content of crude homogenates of rat kidney inner medulla (Fig. $5 B$, lane 2) and comigrated with corresponding bands reported previously (32) to be present in crude membrane fractions of Chinese Hamster ovary cells (Fig. $5 \mathrm{~B}$, lane 1 ). Based on these data, we suggest that both stimulatory $\mathrm{G}_{\alpha q} / \mathrm{G}_{\alpha 11}$ and inhibitory $\mathrm{G}_{\mathrm{i \alpha 1-3}}$ proteins are present in purified AQP-2 endosomes where they may interact with an apical CaR.

In contrast, we detected only two of seven isoforms of PKC using specific antisera (Fig. 5 C). A prominent $78-\mathrm{kD}$ band and a 43-kD band of lesser intensity were identified by anti-PKC delta $(\delta)$ antiserum. In a similar manner, specific bands of 78 and $72 \mathrm{kD}$ that corresponded to the zeta ( $\zeta) \mathrm{PKC}$ isoform was identified by anti-PKC $\zeta$ antiserum (Fig. $5 C$, lane 3). Preincubation of these antisera with specific peptides containing amino acid sequences in the PKC $\delta$ (Fig. $5 C$, lane 2) and $\zeta$ (Fig. $5 C$, lane 4 ) proteins completely ablated binding of the antisera to the respective bands. In contrast, no specific binding of antisera identifying five other PKC isoforms $\left(\alpha, \beta_{1}, \beta_{2}, \gamma\right.$,
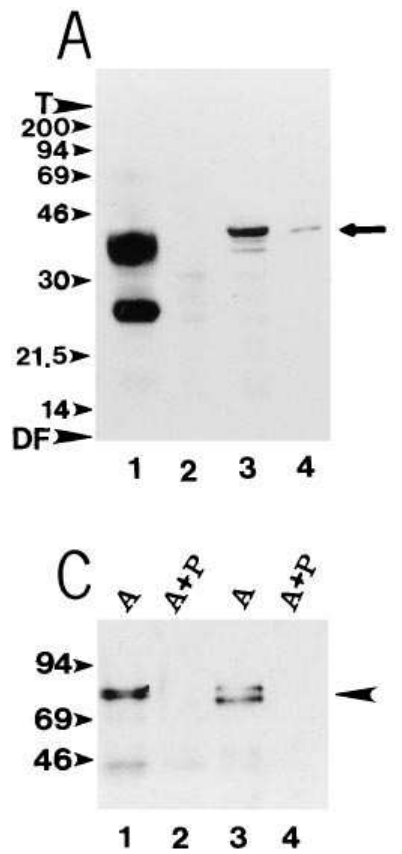
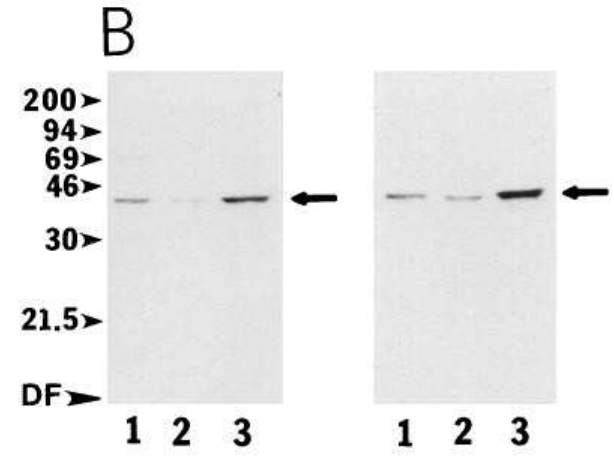

Figure 5. Purified endosomes derived from the apical membrane of the tIMCD contain abundant AQP-2, $\mathrm{G}_{\alpha \mathrm{q}} / \mathrm{G}_{\alpha 11}, \mathrm{G}_{\mathrm{i} \alpha 1-2}$, and $\mathrm{G}_{\mathrm{i} \alpha 3}$, as well as PKC $\delta$ and $\zeta$ isoforms. All individual lanes in $A-C$ contain $40 \mu \mathrm{g}$ protein/lane of either tIMCD homogenate, purified AQP-2 endosomes, or crude membrane fractions from AT-20 or chinese hamster ovary cells that serve as positive controls. All samples were subjected to immunoblotting analyses (16) using various antisera described in Methods. Briefly after exposing nitrocellulose strips derived from individual SDS-PAGE gel lanes to specific primary and secondary antisera, the washed strips were reassembled into units where specific bands on each strip were detected by the electrochemiluminescence technique (16). The resulting three single $\mathrm{x}$-ray films were then used to construct $A-C$. ( $A$ ) Purified endosomes contain AQP-2 and $\mathrm{G}_{\alpha q} / \mathrm{G}_{\alpha 11}$ protein. Prominent AQP-2 bands of 29 and $35-45 \mathrm{kD}$ are observed when endosomes are probed with rabbit antiAPQ-2 antiserum (16) (lane 1). AQP-2 endosomes also contained a $42-\mathrm{kD} \mathrm{G}_{\alpha q} / \mathrm{G}_{\alpha 11}$ protein band (lane 3) that was not present in preimmune antiserum (lane 2) and comigrated with $\mathrm{G}_{\alpha \mathrm{q}} / \mathrm{G}_{\alpha 11}$ protein present in $40 \mu \mathrm{g}$ of protein from mem-

branes of cultured AT-20 parathyroid cells (lane 4). (B) AQP-2 endosomes contain both $\mathrm{G}_{\mathrm{i} \alpha 1-2}$ and $\mathrm{G}_{\mathrm{i} \alpha 3}$ proteins. $\mathrm{G}_{\mathrm{i} \alpha 1-2}($ left $)$ and $\mathrm{G}_{\mathrm{i} \alpha 3}($ right) proteins are enriched in endosomes (lane 3) as compared with tIMCD homogenate (lane 2) and these 41-kD bands comigrate with their respective counterparts present in plasma membrane fraction prepared from cultured Chinese hamster ovary cells (lane 1). This immunoblot is representative of a total of five separate experiments. $(C)$ AQP-2 endosomes contain abundant $\delta$ and $\zeta$ PKC isoforms. Immunoblotting analyses using multiple antisera recognizing seven $\left(\alpha, \beta_{1}, \beta_{2}, \gamma, \delta, \epsilon, \zeta\right)$ distinct PKC isoforms revealed significant staining of only PKC $\delta, 78-\mathrm{kD}$ (lane 1$)$, and $\zeta$ $78 / 72-\mathrm{kD}$ (lane 3 ) species. The five other antisera did not bind to any AQP-2 endosomal proteins (data not shown). The antibody staining was specific since preincubation of antisera with an excess of corresponding peptide ablated both $\delta$ (lane 2 ) and $\zeta$ (lane 4 ) bands. These data are representative of a total of six separate experiments. 
$\epsilon)$ was observed (data not shown). These data suggest that AQP-2 endosomes contain a selected group of PKC isoforms.

\section{Discussion}

Our results provide both functional and structural evidence for a calcium-sensing signal transduction complex present in the apical membrane of rat kidney tIMCD that could possibly integrate calcium and water homeostasis. This putative mechanism represents an important component in an integrated series of kidney epithelial cell transport processes that are modulated by $\mathrm{CaR}$ proteins $(12,28)$. When a systemic calcium load requires renal excretion, small alterations in peritubular calcium concentrations in the cortical TAL reduce its reabsorption of $\mathrm{NaCl}$ and calcium $(30,32,33)$. The resulting CaRmediated reduction in TAL $\mathrm{NaCl}$ and calcium transport causes increases in both urinary $\mathrm{NaCl}$ and calcium that are delivered to the IMCD. However, if maximal AVP-elicited water reabsorption occurs, there is a potential risk of precipitation of calcium oxalate and/or phosphate. The present data indicate that a high luminal calcium concentration could activate the $\mathrm{CaR}$ in the IMCD apical membrane and blunt AVP-elicited $\mathrm{P}_{\mathrm{f}}$ to reduce maximal water reabsorption and prevent a further increase in urinary calcium concentration. In contrast, AVP-elicited increases in tIMCD $\mathrm{P}_{\text {urea }}$ are not affected by alterations in luminal calcium. CaR-mediated reductions in AVP-elicited $\mathrm{P}_{\mathrm{f}}$ would act in concert with the increased luminal $\mathrm{NaCl}$ present in IIMCD that reduces the transepithelial osmotic gradient in the terminal medulla. The magnitude of the specific contributions of the TAL and IMCD to hypercalcemia-induced reductions in urinary concentrating ability will depend on multiple variables including urinary and renal interstitial concentrations of calcium, $\mathrm{NaCl}$, and urea.

These data also provide a unifying explanation for several observations reported previously. Individuals with inactivating CaR mutations (34) are not at increased risk for renal stones and do not have impaired urinary concentrating ability despite persistent hypercalcemia (35). These differences can be attributed to unabated calcium reabsorption in the TAL and maximal urinary concentration in the IMCD. In contrast, individuals with CaR-activating mutations and persistent hypocalcemia suffer from nephrocalcinosis when serum calcium concentrations are elevated to approximately normal levels (36). Inhibition of AVP-elicited $\mathrm{P}_{\mathrm{f}}$ by an apical $\mathrm{CaR}$ could also explain why the maximal urinary concentrating ability of hypercalcemic/hypercalciuric rats remains $\sim 20 \%$ less than controls, even after correction for medullary washout and increased renal prostaglandin production (7). Indeed, recent data from our laboratories demonstrate that a selective blunting of AVP-elicited $\mathrm{P}_{\mathrm{f}}$ but not $\mathrm{P}_{\text {urea }}$ occurs in tIMCD isolated from rats made chronically hypercalcemic/hypercalciuric by dihydrotachysterol intoxication as described in reference 7 (Sands, J., and H.W. Harris, unpublished observations). Similarly, activation of an apical CaR could explain the inhibition of AVP-elicited water flow but not urea or sodium transport upon addition of polycations to the solution bathing the apical membrane of the toad urinary bladder (37). However, data shown in Fig. 1 do not provide definitive proof for the role of $\mathrm{CaR}$ in reducing AVP-elicited $P_{f}$ after inclusion of either increased calcium or neomycin in the IMCD luminal perfusate. While recent patch clamp studies in TAL have demonstrated that neomycin's inhibition of TAL ion transport is specific for its binding to the extracellular not cytoplasmic side of the plasma membrane under conditions where the calcium concentrations of both the bath and pipette solutions are clamped (38), technical obstacles preclude such studies in IMCD cells. Thus, definitive proof of $\mathrm{CaR}$ involvement in IMCD $\mathrm{P}_{\mathrm{f}}$ must await development of specific $\mathrm{CaR}$ antagonists or a detailed characterization of CaR-mediated signal transduction mechanisms in IMCD.

It is well recognized that alterations in IMCD AVP-elicited $\mathrm{P}_{\mathrm{f}}$ occur by the insertion and removal of AQP-2 water channels $(13,14,16,21)$. Insertion of AQP-2 vesicles into the IMCD apical membrane is mediated via an increase in intracellular cAMP while reductions in AVP-elicited $\mathrm{P}_{\mathrm{f}}$ are accompanied by endocytosis of AQP-2 vesicles from the apical membrane (21). Data from many laboratories have demonstrated that AVP-elicited apical membrane events that increase $\mathrm{P}_{\mathrm{f}}$ are antagonized by activation of PKC $(39,40)$.

On the basis of our results, we suggest a model where $\mathrm{CaR}$, $\mathrm{G}_{\alpha \mathrm{q}} / \mathrm{G}_{\alpha 11}, \mathrm{G}_{\mathrm{i} \alpha 1-3}$, and the $\mathrm{Ca}^{2+}$-independent PKC $\delta$ and $\zeta$ isoforms in purified AQP-2 endosomes may provide a means to integrate changes in luminal calcium into alterations in the membrane trafficking of AQP-2 and subsequent modulation of $\mathrm{P}_{\mathrm{f}}$. CaR activation increases phosphoinositide-specific phospholipase $C(9,11,29)$, yielding products that have been shown to modulate $\mathrm{NaCl}$ transport in the TAL (30), alter secretion and endocytosis in various tissues (27), as well as activate PKC $\delta$ and $\zeta(41)$. G proteins, particularly $\mathrm{G}_{\mathrm{i} \alpha 3}$, have also been implicated in regulation of membrane trafficking in the secretory pathway in renal epithelial cells (42) and are demonstrated to be complexed with an amiloride-inhibitable sodium channel located in the apical membrane of the IMCD (43). While the details of such a putative $\mathrm{CaR}$ membrane signaling complex remain to be defined, it is noteworthy that rat AQP-2 contains a consensus PKC phosphorylation site in its cytoplasmic carboxyl terminus (13) and that PKC $\zeta$ is a component of purified synaptic vesicles in the brain (44) that are similar to purified AQP-2 endosomes $(20,45)$. Our data showing the presence of individual $\mathrm{PKC}$ isoforms as components of endosomes derived from the IMCD apical membrane further refine knowledge of specific PKC isoforms in tIMCD function $(39,40)$.

Future work may provide new insights into abnormalities of renal water conservation and calcium homeostasis in humans that contribute to the pathogenesis of renal stone formation. In this regard, our localization of CaR to epithelial cells in human collecting duct (Fig. 3) represents an initial step in this effort. Moreover, these data could also serve as a model for study of the regulation of ion transport in other epithelial cell types including the renal distal tubule, where alterations in luminal calcium have also been reported to alter potassium transport (46).

\section{Acknowledgments}

Support for this research was provided by NPS Pharmaceuticals Inc., Salt Lake City, UT and the St. Giles Foundation (S.C. Hebert and E.M. Brown) as well as National Institutes of Health grants DK38874, DK-43955, and HL-15157 (H.W. Harris); DK-48330 (E.M. Brown and S.C. Hebert), DK-41415 and DK-44588 (E.M. Brown), and DK-45688 and DK-41707 (J.M. Sands).

\section{References}

1. Asplin, J., M.J. Favus, and F.L. Coe. 1996. Nephrolithiasis. In The Kidney. Edited by B.M. Brenner. W.B. Saunders Co., Philadelphia. 1893-1935. 
2. Johnson, C.M., D.M. Wilson, W.M. O'Fallon et al., 1979. Renal stone epidemiology: a 25 year study in Rochester, Minnesota. Kidney Int. 16:624-631.

3. Hodgkinson, A., and L. Pyrah. 1958. The urinary excretion of calcium and inorganic phosphate in 344 patients with calcium stones of renal origin. $\mathrm{Br}$. J. Surg. 46:10-18.

4. Jacobson, A., P. Singhal, H. Mandin, and J. Hyne. 1979. Urinary ionic calcium and binding sites in normocalciuric idiopathic calcium urolithiasis. Invest. Urol. 17:218-231.

5. Frank, M., A. De Vries, J. Lazebnik, and S. Kochwa. 1959. Epidemiological investigations of urolithiasis in Israel. J. Urol. 81:497-504.

6. Straus, A.L., F.L. Coe, and L. Deutsch. 1982. Factors that predispose to relapse of calcium nephrolithiasis during treatment. A prospective study. Am. J. Med. 72:17-23.

7. Levi, M., L. Peterson, and T. Berl. 1983. Mechanism of concentrating defect in hypercalcemia. Role of polydyspsia and prostaglandins. Kidney Int. 23: 489-497.

8. Takaichi, K., and K. Kurokawa. 1988. Inhibitory guanosine triphosphatebinding protein-mediated regulation of vasopressin action in isolated single medullary tubules of mouse kidney. J. Clin. Invest. 82:1437-1444.

9. Brown, E., et al., 1993. Cloning and characterization of an extracellular $\mathrm{Ca}^{2+}$-sensing receptor from bovine parathryoid. Nature (Lond.). 366:575-580.

10. Garrett, J.E., et al., 1995. Molecular cloning and functional expression of human parathyroid calcium receptor cDNAs. J. Biol. Chem. 270:1291912925

11. Riccardi, D., et al. 1995. Cloning and functional characterization of a rat kidney extracellular calcium/polyvalent ion cation-sensing receptor. Proc. Nat. Acad. Sci. USA. 92:131-135.

12. Brown, E.M., et al. 1995. Calcium-ion-sensing cell surface receptors. $N$. Engl. J. Med. 333:234-240.

13. Fushimi, K., et al. 1993. Cloning and expression of apical membrane water channel of rat kidney collecting tubule. Nature (Lond.). 361: 549-552.

14. Neilsen, S., S.R. DiGiovanni, E.I. Christensen, M.A. Knepper, and H.W. Harris. 1993. Cellular and subcellular immunolocalization of vasopressinregulated water channel in rat kidney. Proc. Nat. Acad. Sci. USA. 90:1166311667

15. Sands, J.M., H. Nonoguchi, and M.A. Knepper. 1987. Vasopressin effects on urea and $\mathrm{H}_{2} \mathrm{O}$ transport in inner medullary collecting duct subsegments. Am. J. Physiol. 253:F823-F832.

16. Harris, H.W., M.L. Zeidel, I. Jo, and T.G. Hammond. 1994. Characterization of purified endosomes containing the antidiuretic hormone sensitive water channel from rat renal papilla. J. Biol. Chem. 269:11993-12000.

17. Clapp, W.L., K.M. Madsen, J.W. Verlander, and C.C. Tisher. 1989. Morphologic heterogeneity along the rat inner medullary collecting duct. Lab. Invest. 60:219-223.

18. Paredes, A., D.M. Briscoe, C.K. Williams, A. Garcia-Perez, J.B. Wade, and H.W. Harris. 1994. Water channel vesicles from toad urinary bladder contain a family of proteins distributed in selected cell types in other tissues. Am. J. Physiol. 266:C1366-C1375

19. Chattopadhyay, N., M. Baum, M. Bai, D. Riccardi, S.C. Hebert, H.W. Harris, and E.M. Brown. 1996. Ontogeny of the extracellular calcium-sensing receptor in rat kidney. Am. J. Physiol. 271:F736-F743.

20. Jo, I., H.W. Harris, A.M. Amendt-Raduege, R.R. Majewski, and T.G. Hammond. 1995. Rat kidney papilla contains abundant synaptobrevin protein that participates in fusion of antidiuretic hormone (ADH) water channel containing endosomes. Proc. Nat. Acad. Sci. USA. 92:1876-1880.

21. Neilsen, S., J. Muller, and M.A. Knepper. 1993. Vasopressin- and cAMP-induced changes in ultrastructure of isolated perfused inner medullary collecting ducts. Am. J. Physiol. 265:F225-F238.

22. Flamion, B., and K.R. Spring. 1990. Water permeability of apical and basolateral cell membranes of rat inner medullary collecting duct. Am. J. Physiol. 259:F986-F999.

23. Star, R.A., H. Nonoguchi, R. Balaban, and M.A. Knepper. 1998. Calcium and cyclic adenosine monophosphate as second messengers for vasopressin in the rat inner medullary collecting duct. J. Clin. Invest. 81:1879-1888.

24. Ishibashi, K., et al. 1994. Molecular cloning and expression of a member of the aquaporin family with permeability to glycerol and urea in addition to water expressed at the basolateral membrance of kidney collecting duct cells. Proc. Natl. Acad. Sci. USA. 91:6269-6273.

25. Frigeri, A., M.A. Gropper, C.W. Turck, and A.S. Verkman. 1995. Immunolocalization of the mercurial-insensitive water channel and glycerol intrinsic protein in epithelial cell plasma membranes. Proc. Natl. Acad. Sci. USA. 92: 4328-4331.

26. Varrault, A. et al. 1995. Expression of $\mathrm{G}$ protein $\alpha$-subunits in bovine parathyroid. Endocrinology. 136:4390-4396.

27. Tamir, H., L. Kuo-Peing, M. Adlersberg, S.-C. Hsiung, and M.D. Gershon. 1996. Acidification of serotonin-containing secretory vesicles induced by a plasma membrane calcium receptor. J. Biol. Chem. 271:6441-6450.

28. Brown, E.M., H.W. Harris, P.M. Vassilev, and S.C. Hebert. 1997. The biology of the calcium receptor. In The Biology of Bone. L. Raisz, G. Rodan, and J.P. Bilezikian, editors. Academic Press Inc, New York. Chapter 23.

29. Pollak, M. et al., 1994. Autosomal dominant hypocalcemia caused by a $\mathrm{Ca}^{2+}$-sensing receptor gene mutation. Nat. Genet. 8:303-307.

30. Hebert, S.H., E.M. Brown, and H.W. Harris. 1997. Role of the $\mathrm{Ca}^{2+}$ sensing receptor in divalent mineral homeostasis. J. Exp. Biol. In press.

31. DeCamilli, P., S.D. Emr, P.S. McPherson, and P. Novick. 1996. Phosphoinositides as regulators in membrane traffic. Science (Wash. DC). 271:15331539 .

32. Lynch, C.J., P.F. Blackmore, E.H. Johnson, R.L. Wagne, P.K. Krone, and J.H. Exton. 1989. Guanine nucleotide binding regulatory proteins and adenylate cyclase in livers of streptozotocin and BB/Wor-Diabetic rats. J. Clin. Invest. 83:2050-2062.

33. Quamme, G.A. 1989. Control of magnesium transport in thick ascending limb. Am. J. Physiol. 256:F197-F210.

34. Pollak, M., et al. 1993. Mutations in the human $\mathrm{Ca}^{2+}$-sensing receptor gene cause familial hypocalciuric hypercalcemia and neonatal severe hyperparathyroidism. Cell. 75:1297-1301.

35. Marx, S.J., M.F. Attie, J.L. Stock, A.M. Spiegel, and M.A. Levine. 1981. Maximal urine-concentrating ability: familial hypocalcuric hypercalcemia versus typical primary hyperparathyroidism. J. Clin. Endocrinol. Metab. 52:736740

36. Davies, M., Z. Mughal, P.L. Selby, D.J. Tymms, and E.B. Mawer. 1995. Familial benign hypocalcemia. J. Bone Miner. Res. 10:S507.

37. Beauwens, R., G. Te Kronnie, J. Snauwaert, and P.A. In’t Veld. 1986. Polycations reduce vasopressin-induced water flow by endocytic removal of water channels. Am. J. Physiol. 250:C729-C737.

38. Wang, W., M. Lu, and S.C. Hebert. 1996. Phospholipase A2 mediates the inhibitory effect of increasing extracellular calcium on the apical $\mathrm{K}+$ channel in the thick ascending limb. J. Am. Soc. Nephrol. 7:1294.

39. Breyer, M., and Y. Ando. 1994. Hormonal signaling and regulation of salt and water transport in the collecting duct. Annu. Rev. Physiol. 56:711-739.

40. Teitelbaum, I. 1992. Hormone signaling systems in inner medullary collecting duct. Am. J. Physiol. 263:F985-F990.

41. Hug, H., and T.F. Sarre. 1993. Protein kinase C isoenzymes: divergence in signal transduction. Biochem. J. 291:329-343.

42. Stow, J.L., and J.B. de Almeida. 1993. Distribution and role of heterotrimeric $\mathrm{G}$ proteins in the secretory pathway of polarized epithelial cells. J. Cell Sci. 17:33-39.

43. Ausiello, D.A., J.L. Stow, H.F. Cantiello, J.B. de Almeida, and D.J. Benos. 1992. Purified epithelial $\mathrm{Na}^{+}$channel complex contains the pertussis toxin-sensitive G alpha i-3 protein. J. Biol. Chem. 267:4759-4765.

44. Prekeris, R., M.W. Mayhew, J.B. Cooper, and D.M. Terrian. 1996. Identification and localization of an actin-binding motif that is unique to the epsilon isoform of protein kinase $\mathrm{C}$ and participates in the regulation of synaptic function. J. Cell Biol. 132:77-90.

45. Nielsen, S., et al. 1995. Expression of VAMP2-like protein in kidney collecting duct intracellular vesicles. J. Clin. Invest. 96:1834-1844.

46. Okusa, M.D., H. Velazquez, D.H. Ellison, and F.S. Wright. 1990. Luminal calcium regulates potassium transport by the renal distal tubule. Am. J. Physiol. 258:F423-F428. 